\title{
In situ study of the autecology of the closely related, co-occurring sandy beach amphipods Bathyporeia pilosa and Bathyporeia sarsi
}

\author{
Jeroen Speybroeck $\cdot$ Joke Van Tomme $\cdot$ Magda Vincx $\cdot$ \\ Steven Degraer
}

Received: 28 March 2008 / Revised: 28 March 2008 / Accepted: 16 April 2008 / Published online: 17 June 2008

(C) Springer-Verlag and AWI 2008

\begin{abstract}
Population dynamics and zonation of the amphipods Bathyporeia pilosa and B. sarsi, co-occurring on some beaches, were studied through monthly sampling of eight cross-shore transects along the Belgian coast (October 2003-October 2004). Their biomass and production were assessed for the first time. Abundance and biomass of B. pilosa were ten times higher along western ultradissipative transects than along slightly more reflective, eastern transects. For $B$. sarsi (less prominent), differences between the two westernmost transects $(2-5 \times$ higher $)$ and all others were observed, whereas $\mathrm{P} / \mathrm{B}$ ratio was comparable for all. B. pilosa could reach two times higher abundance and biomass and higher levels of production (max B. sarsi $=7,580 \mathrm{~g} \mathrm{~m}^{-2} \mathrm{y}^{-1} ; \max$ B. pilosa $=16,040 \mathrm{~g}$ $\mathrm{m}^{-2} \mathrm{y}^{-1}$ ), while the species was nearly absent from the eastern transects. Continuous reproduction and recruitment with three relative peaks of the latter (February, July, October) were observed. Fecundity showed parallel temporal variation for both species, peaking in February and September-October. Interestingly, the July relative "recruitment" peak could not be explained by relative abundance of gravid females or fecundity, but was probably caused by adult mortality. Both species displayed comparable gonad production (B. pilosa: $P_{g}=0.73 \mathrm{mg} /$ ind year; $B$. sarsi: $P_{g}=0.71 \mathrm{mg} /$ ind year), but $B$. pilosa produced fewer yet larger embryos. Peak abundances were found at $436 \pm 25 \mathrm{SD} \mathrm{cm}$ (B. pilosa) and $357 \pm 40 \mathrm{SD} \mathrm{cm}$ (B. sarsi) above MLLWS, corresponding to a 40-62 m cross-shore
\end{abstract}

Communicated by H.-D. Franke.

J. Speybroeck $(\varangle) \cdot$ J. Van Tomme $\cdot$ M. Vincx $\cdot$ S. Degraer

Marine Biology Section, Ghent University,

Krijgslaan 281, Building S8, 9000 Ghent, Belgium

e-mail: jeroenspeybroeck@ hotmail.com distance between the peaks of both species. The occupied cross-shore range was larger for $B$. sarsi than for B. pilosa (35-54 m), for females than for males (15-23 m), and for adults than for juveniles of $B$. pilosa $(5-8 \mathrm{~m})$. Both species displayed many comparable life history features. Differences in abundance and biomass may be related to beach morphodynamics and zonation.

Keywords Sandy beaches · Population dynamics . Amphipods $\cdot$ Zonation $\cdot$ Bathyporeia

\section{Introduction}

Bathyporeia pilosa and Bathyporeia sarsi are common amphipod species of beaches of the eastern Atlantic, from Norway to France (Gulf of Biscay), with B. sarsi stretching even a little further south until southern Portugal (Marques and Bellan-Santini 1991). Bathyporeia pilosa is found in the upper parts of the intertidal zone of sheltered beaches, between mean high water springs (MHWS) and mid-tide level (Fish and Preece 1970a); in the retention zone and the upper parts of the resurgence zone, but not in the saturation zone (Salvat 1962, 1964). It is absent from strongly exposed beaches (Vader 1965), yet also encountered in subtidal areas, namely in estuarine and brackish conditions (Lindström 1855; Dahl 1944; Vader 1966; Persson 1982; Köhn and Gosselck 1989). Slight morphological differences have been observed between intertidal and subtidal populations (d'Udekem d'Acoz 2004), which may provoke doubt on the conspecifity of those populations. Along an open coastline, B. sarsi is a strictly intertidal species (Toulmond 1964; Vader 1965), where it can be found between mean high water neaps $(\mathrm{MHWN})$ and mean low water springs (MLWS) (Toulmond 1964). In some estuaries, however, 
the species has been found to live below the low water line (Vader 1965, 1966; Degraer et al. 2002). On Belgian beaches, $B$. pilosa is a species of 'drying sands' (around MHWN), while $B$. sarsi is said to occur somewhat below it (Degraer et al. 2003). Both species can be highly abundant; in Belgium they can frequently be found together on the same beaches, reaching abundances of up to $10,000 \mathrm{ind} / \mathrm{m}^{2}$ (Degraer et al. 2003). These high numbers of amphipods are of high importance as food source for wading birds (mainly Sanderling (Calidris alba) and surf zone fish (Lasiak 1983; Nicolaisen and Kanneworff 1983; Gibson and Robb 1996) such as juvenile plaice (Pleuronectes platessa) (Beyst et al. 2002) and sand-eel species such as Ammodytes tobianus (Persson 1982). Both Bathyporeia species are said to feed solely on epipsammic food items and their mouthparts are considered to be specialised for that purpose (Nicolaisen and Kanneworff 1969). Diatoms (and more specifically species of the genus Coconeis) comprise an important part of their diet (Nicolaisen and Kanneworff 1969; Sundbäck and Persson 1981).

While B. pilosa has been studied rather well (Vader 1965, 1966; Nicolaisen and Kanneworff 1969, 1983; Fish and Preece 1970a, b; Preece 1970, 1971a, b; Fish 1975; Khayrallah and Jones 1980a, b; Sundbäck and Persson 1981; Persson 1982; Mettam 1989; Köhn and Sammour 1990), far less is known on the ecology of B. sarsi (Vader 1965, 1966; Nicolaisen and Kanneworff 1969, 1983; Bamber 1993). Several studies have focused on B. pilosa and a third species, B. pelagica (Fish and Preece 1970a, b; Preece 1971a; Fish 1975). To a certain degree, B. sarsi might be regarded as intermediate between $B$. pilosa and $B$. pelagica concerning a number of ecological traits, e.g., cross-shore distribution and substrate preferences (Vader 1965, 1966). Only occasionally their syntopic occurrence on beaches has been investigated (Vader 1965, 1966; Nicolaisen and Kanneworff 1969, 1983). Thus, a combined ecological study of B. pilosa and B. sarsi was conducted on their life histories, population dynamics and zonation patterns, trying to unravel elements of their interspecific ecological segregation in co-occurrence. The first published assessment of biomass and secondary production of these sandy beach key species is presented. Tests were conducted to identify significant spatial and temporal patterns. Based on literature data, we a priori hypothesised $B$. pilosa to be the more stress-tolerant species, due to life higher up on the beach. We expected interspecific differences in population dynamics related to these different environmental conditions.

\section{Methods}

Sampling

Along the Belgian shore, eight cross-shore transects were sampled monthly from October 2003 until October 2004, January 2004 excluded (Fig. 1). Sampling started each time at high tide and continued until the low tide level was reached, taking a sample every half hour just above the upper swash limit. In order to minimise differences in tidal range among sampling months, sampling dates related to a fixed point in the lunar spring-neap cycle. Each sample involved a $0.1026 \mathrm{~m}^{2}$ rectangle being dug out to a depth of $20 \mathrm{~cm}$ and sieved at $1 \mathrm{~mm}$ mesh width. An additional sample was taken for sediment analysis. Elevation of sampling stations and the entire beach profile were measured using a leveller and corroborated afterwards with the output of the M2 tidal reduction model (Coastal Division of the Agency of Maritime and Coastal Services).
Fig. 1 Location of sampled transects along the Belgian coast; $N P$ Nieuwpoort-Bad, IJZ beach of flemish nature reserve "Ijzermonding", $M K$ Middelkerke-Bad, $O O$ OostendeBad. Capitals $A$ and $B$ are to identify the two transects within the same beach

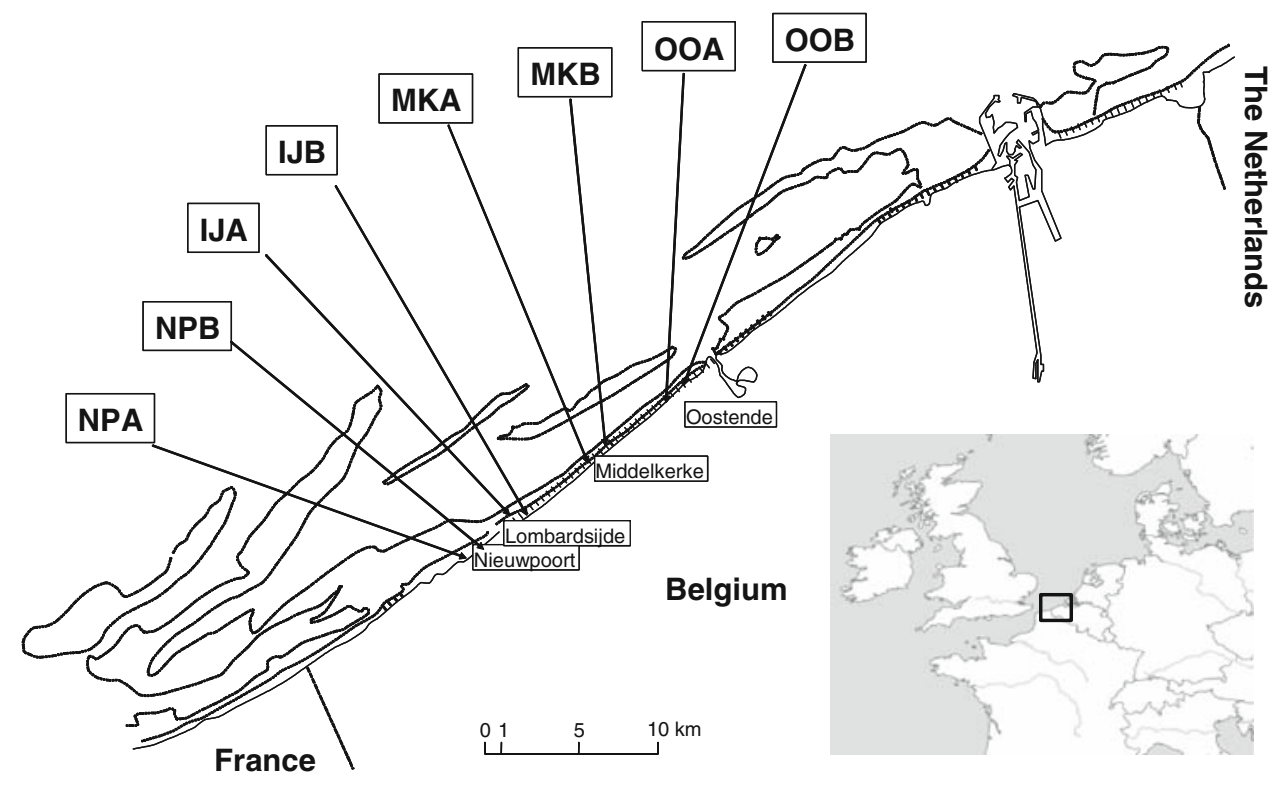


On two occasions, a part of the data was omitted from the analysis. First, after the Oostende nourishment of June 2004, involving nourishment of the previously selected OOB transect, samples from the affected transect were not considered anymore. Furthermore, due to an unanticipated low elevation of high tide and high elevation of low tide, sampling in September 2004 covered a clearly smaller tidal range than during the other sampling months. This resulted in incomplete sampling of the populations of B. pilosa, and therefore this month was left out from further analysis of the data for that species.

\section{Laboratory procedures}

Species identification was achieved with d'Udekem d'Acoz (2004). To obtain a length-biomass regression, allowing calculation of biomass from measurement data, 100 undamaged specimens of both species and all sizes were randomly collected from March (50 ind.) and September (50 ind.) samples. Total body length was measured as in Persson (1982): from the basal segment of the first antenna or antennule (pseudorostrum) to the end of the telson. Fish and Preece (1970a) and Mettam (1989) chose to measure body length until the spine of the fourth pleon segment. We believe measurement of the entire body to be preferable, even though this might somewhat limit the comparability of studies. One hundred specimens of each species were dried $\left(4 \mathrm{~h}\right.$ at $\left.110^{\circ} \mathrm{C}\right)$ and dry weight was established. Subsequent combustion $(2 \mathrm{~h}$ at $550^{\circ} \mathrm{C}$ ) delivered the specimens' ash weight and subtraction of both weights delivered ash-free dry weight (AFDW). After log transformation of the biomass data and having ensured that assumptions were met, linear regression analyses was executed. Thus, with the obtained equations (B. pilosa: $R^{2}=0.863, p<0.01, d f(1.86) ; B$. sarsi: $R^{2}=0.885, p<0.01, d f(1.97)$ and measurement of body length of all collected specimens (10.588 individuals of B. pilosa and 3.275 of B. sarsi), AFDW was calculated. Three percent of the collected specimens (495 individuals) were damaged to a degree that they could not be identified to species level. These specimens were omitted from the data.

Individuals were counted and identified as males, females and juveniles according to Watkin (1938). Stations delivering zero values (lower intertidal area) have been omitted to obtain values of abundance and biomass, relating to the occupied long-shore strip of the beach only. Embryos, if present within the female's brood pouch, were counted to assess fecundity.

For B. pilosa, zonation was studied based only on the western transects (IJA, IJB, NPA and NPB) because their numbers at the eastern transects (MKA, MKB, OOA en OOB) are very low.
Data analysis

Count data were used for abundance-related analysis. Biomass calculation allowed calculation of secondary production, using the size frequency method (SFM: Hynes and Coleman 1968): $E_{j-j+1}=\left(M_{j}+\mathrm{M}_{j+1}\right)^{0.5} \times\left(N_{j}-N_{j+1}\right)$; with $M_{j}$ and $M_{j j}+1$ being the mean biomasses for respectively size classes $j$ and $j+1$, and $N_{j}$ and $N_{j+1}$ being the mean number of individuals in respectively classes $j$ and $j+1$. Elimination of the average cohort (as all cohorts are spread over the applied size classes and maximum life span is not taken into account yet) is given by: $E_{\mathrm{ac}}=\Sigma\left(E_{j-j+1}\right)$; with $j=(1,2,3, \ldots m)$. Production equals elimination of the entire population, taking life span $\left(A_{\max }\right)$ and number of size classes $(m)$ into account: $E=E_{\mathrm{ac}} \times m / A_{\max }$. Female gonad production, relating to gonadal products released between times $t$ and $t+1$ was calculated with the formula for direct measurement: $P_{g \text { ind } t=>t-1}=\Sigma N_{e g} \times M_{e g g}$ (egg mass ind ${ }^{-1}$ time $^{-1}$ ). Cohort analysis (decomposition of size-frequency distributions into Gaussian components with Bhatthacharya's method (Bhatthacharya 1967) and NORMSEP (Hasselblad 1966; Tomlinson 1971) was conducted with FiSat II software (Gayanilo et al. 1996). Due to the confusing output of the cohort analysis, no von Bertalanffy growth function was fit, nor was the instantaneous mortality rate calculated, but this had no further bearing on other estimates of population characteristics, except for a more indirect determination of the adult life span.

Due to its more descriptive rather than predictive capacity (Short 1999), the beach index (BI) (McLachlan and Dorvlo 2005) was preferred over the more conventional Dean's parameter and relative tidal range parameters for characterisation of morphodynamics: $\mathrm{BI}=\log \left(\left(-\log _{2}\right.\right.$ $($ median grain size in $\mu \mathrm{m})+1) \times$ tidal range)/slope. Given the spatial (intra-transect comparisons; zonation patterns) and temporal (monthly sampling at the same exact transect locations) dependent nature of the data, statistical tests were chosen accordingly.

\section{Results}

Due to the strong connectivity of the marine environment, we consider the entire Belgian coastline to harbour a single population of each species. Therefore, transects can be regarded as samples of one population. This was confirmed by the fact that the observed differences in abundance, biomass, production and zonation, were related to small-scale variation of the physical environment rather than to the geographical position of the transects; no spatial variation was observed in most of the population characteristics. In our analysis, no beach effect was evident (among-transect variation comparable to or even less than among-beach 
variation), thus transects could be used as independent replicates. Given the dependent nature of the data and the type of statistical tests used, spatial comparison (between transects) was, however, possible using sampling months as repeated observations on the same items.

\section{Physical environment}

All sampled beaches are wide, macrotidal beaches with an intertidal beach width from about 170 to over $200 \mathrm{~m}$ and an average spring tide tidal range of $4.5-4.7 \mathrm{~m}$. Beach slope was weak $\left(0.75-1.15^{\circ}\right)$. Sediment analysis showed median grain size to range from 171 to $347 \mu \mathrm{m}$ and the sediment to be well to moderately well sorted $(\mathrm{SD}=1.29-1.58 \mu \mathrm{m})$. With a beach index (BI) of 2.7 to 3.0, the morphodynamic type of all four beaches is clearly dissipative, in concordance to Degraer et al. (2003). Western transects have, however, higher beach index values $(\mathrm{BI}=2.95 \pm 0.03 \mathrm{SD})$ than eastern ones $(\mathrm{BI}=2.75 \pm 0.03 \mathrm{SD}$ ) (Mann-Whitney $U$ Test: $Z=2.12 ; p=0.03$ ), suggesting eastern transects to be a little less dissipative. Significant differences between transects were found in median grain size (Friedman $\chi^{2}(N=4$, $d f=6)=22.39 ; p<0.01$ ). Western transects (IJA, IJB, NPA, NPB) exhibit lower median grain sizes, especially those from Nieuwpoort (NP; e.g. NPB: $192 \pm 6$ SD $\mu \mathrm{m}$ ), whereas grain size on Middelkerke and Oostende beaches seems comparably larger (e.g., MKB: $268 \pm 24$ SD $\mu \mathrm{m}$ ).

Fines $(<63 \mu \mathrm{m})$ were encountered in minor quantities at western transects (highest in NPB: $0.14 \pm 1.00 \mathrm{SD} \%$, but at least $4 \times$ less in other western transects), and were usually completely absent from eastern transect sediment samples.

\section{Abundance and biomass}

While sampled transects were selected as morphodynamically highly similar, data analysis revealed some clear spatial variation regarding the abundance and biomass of the Bathyporeia populations. Concerning B. pilosa, a sharp distinction can be made between western and eastern transects, with significantly higher abundance [Friedman $\chi^{2}$ Square $(N=11, d f=6)=51.74 ; p<0.01]$ (Fig. 2) and biomass [Friedman $\chi^{2}$ Square $(N=11, d f=6)=41.63 ; p<0.01$ ] on western ones. Whereas western abundance averages were all above $150 \mathrm{ind} / \mathrm{m}^{2}$, eastern ones were lower than $10 \mathrm{ind} /$ $\mathrm{m}^{2}$. Biomass supports the same distinction, with values ranging from $3 \pm 5 \mathrm{SD} \mathrm{mg} / \mathrm{m}^{2}$ for MKA to $714 \pm 476 \mathrm{SD}$ $\mathrm{mg} / \mathrm{m}^{2}$ for IJA.

Also $B$. sarsi shows significant differences between transects regarding both abundance [Friedman $\chi^{2}$ Square $(N=9, d f=6)=35.48 ; \mathrm{p}<0.01$ ] and biomass [Friedman $\chi^{2}$ Square $(N=9, d f=6)=25.19 ; p<0.01]$, but with a different grouping. In this species, only the Nieuwpoort transects had higher densities (averages of more than $125 \mathrm{~m}^{2} / \mathrm{ind}$ ), while all other beaches maintained moderate densities of the species (averaging at $40 \mathrm{ind} / \mathrm{m}^{2}$ ). The difference between transects was clearly not as strong as with $B$. pil$o s a$, and all transects seem to maintain viable populations of $B$. sarsi. From a comparison, we can conclude that $B$. pil$o s a$ is significantly more abundant on the IJA, IJB and NPA transects [Wilcoxon matched pairs test: respectively $Z=2.82$ and $p<0.01 ; Z=2.43$ and $p=0.02 ; Z=2.51$ and $p=0.01]$, while $B$. sarsi is significantly more abundant than B. pilosa on MKA, MKB and OOA transects [Wilcoxon matched pairs test: respectively $Z=3.06$ and $p<0.01$; $Z=2.12$ and $p=0.03 ; Z=3.06$ and $p<0.01$ ). Finally, both occur in comparable numbers on the NPB transect (Wilcoxon matched pairs test: $Z=0.40$ and $p<0.69$ ).

Maximum observed densities were $8,209 \mathrm{ind} / \mathrm{m}^{2}$ for $B$. pilosa (NPA in July 2004) and $2,205 \mathrm{ind} / \mathrm{m}^{2}$ for $B$. sarsi (NPB in May 2004).

While no significant temporal variation was observed for B. pilosa [abundance: Friedman $\chi^{2}$ Square $(N=3$, $d f=10)=10.18, p=0.42$; biomass: Friedman $\chi^{2}$ Square $(N=3, d f=10)=8.08, p=0.21]$, both numbers and biomass of $B$. sarsi peaked in spring and were lowest in autumn and winter [abundance: Friedman $\chi^{2}$ Square $(N=4$, $d f=11)=21.80, p=0.03$; biomass: Friedman $\chi^{2}$ Square $(N=4, d f=11)=11.87, p<0.01]$.
Fig. 2 Spatial variation of abundance of Bathyporeia pilosa (left) and B. sarsi (right). Box SE, whisker SD. Transects ordered from west (left) to east (right) in both graphs
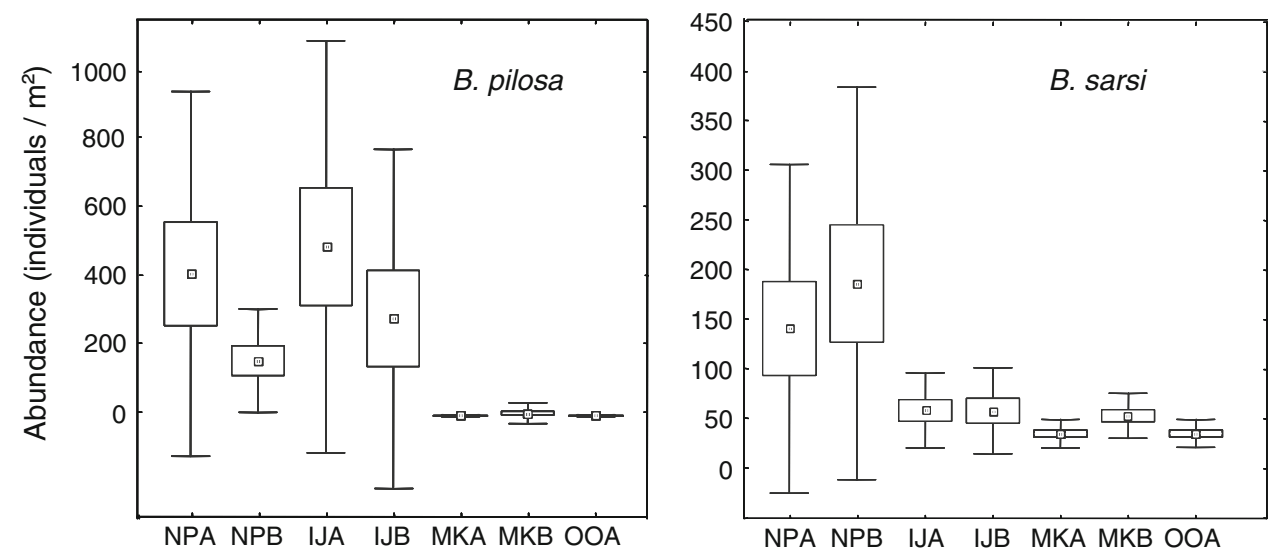
Furthermore, significant differences in size between the two species were found (Wilcoxon matched pairs test: $Z=2.90$ and $p<0.01)$, with $B$. sarsi $(6.10 \pm 0.68 \mathrm{SD} \mathrm{mm})$ being about $10 \%$ larger than $B$. pilosa $(5.45 \pm 0.73 \mathrm{~mm})$.

Life cycle, demography, reproduction and recruitment

Cohort analysis for both species delivered confusing results, making it impossible to track down any age group through time. Therefore, we refrain from any, inevitably confusing, graphic representation. A nine months maximal adult life span could be deduced from partially traceable cohorts of both species. Arrival of new, small B. pilosa individuals (i.e., recruitment) was observed e.g., in October, with an average length of $3.11 \mathrm{~mm}$ in 2003 and $3.86 \mathrm{~mm}$ in 2004. Another peak in recruitment was observed in February, with individuals of $4.08 \mathrm{~mm}$ of average length. Tracing the life history of individual cohorts from month to month proved to be very difficult, if not impossible. This suggests reproduction and recruitment to be continuous with merging and re-splitting of groups of recruits of the same age. The February 2003 recruitment cohort could be traced somewhat more clearly than that of October 2003, growing from February until SeptemberOctober. Besides the juvenile cohort in February, a second cohort was present of $5.98 \mathrm{~mm}$ in average size. This cohort consisted most likely of recruits of October 2003, giving raise to peak recruitment in October 2004 before dying.

In $B$. sarsi, as in B. pilosa, a new cohort appeared in October [average size: $4.22 \mathrm{~mm}$ in 2003; $4.52 \mathrm{~mm}$ in 2004]. Also another recruitment peak could be observed in February (average size: $4.39 \mathrm{~mm}$ ).

Again, drawing temporal growth patterns for single cohorts was hardly possible. The cohort of October (2003) recruits collided with a group of larger and older individuals in December. Like with B. pilosa, the February recruits were a little easier to follow during the consecutive months, but became indistinguishable from another cohort in June and August.

The relative abundance of gravid, egg-bearing females displayed two peaks for both species: a spring peak in April and another one in autumn (September-October), separated by low values in winter (December) and summer (July) were observed (Fig. 3). In B. pilosa, the spring adult cohort responsible for peak reproductive activity contained individuals of $5.98 \mathrm{~mm}$ on average; those of October 2004 were of $5.05 \mathrm{~mm}$ on average, while in October 2003 two nonjuvenile cohorts seemed to be present $(5.88$ and $4.26 \mathrm{~mm}$ on average). A comparable pattern was observed for $B$. sarsi: from February onwards the relative number of gravid females increased, peaking in May, dropping to a July low and peaking again in autumn (October). However, the relative abundance apparently can differ strongly between

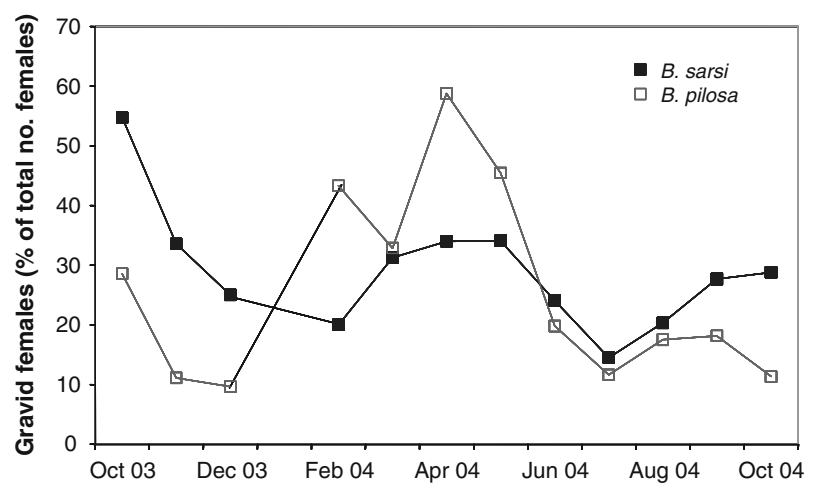

Fig. 3 Temporal variation of relative number of gravid females (\% of total number of females). Error bars omitted for graphic representation

years: 55\% in October 2003 and only 29\% in October 2004 for $B$. sarsi, and $29 \%$ versus $11 \%$ in the same years for $B$. pilosa (Fig. 3).

Fecundity patterns were even clearer (Fig. 4). B. sarsi females carried about 1.75 times as much eggs as females of $B$. pilosa (Wilcoxon matched pairs test: $Z=5.07 ; p<0.01$ ), whereas the weight of an individual B. pilosa egg was about 1.8 times the weight of one belonging to $B$. sarsi. Thus, total carried egg mass was comparable for both species and this is confirmed by their gonad production values (B. pilosa: $P_{\mathrm{g}}=0.73 \mathrm{mg} /$ ind year; $B$. sarsi: $P_{\mathrm{g}}=0.71 \mathrm{mg} /$ ind year $)$. Fecundity peaked for both species in February 2004 and was lowest in August 2004, the latter low coinciding with rather low numbers of gravid females for both species. Both species showed a weak correlation between female size and egg load (Spearman rank order correlation: $B$. pilosa: $\mathrm{SR}=0.35$; $p<0.01 ;$ B. sarsi: $\mathrm{SR}=0.33 ; p<0.01)$.

Juvenile abundance (expressed as the proportion of juveniles in the entire population), expected to result from the combined variation in both number of gravid females and fecundity, shows a February-March, a July and an October peak for both species (Fig. 5). Peaks were more pronounced in B. pilosa, indicating somewhat less continuous recruitment patterns.

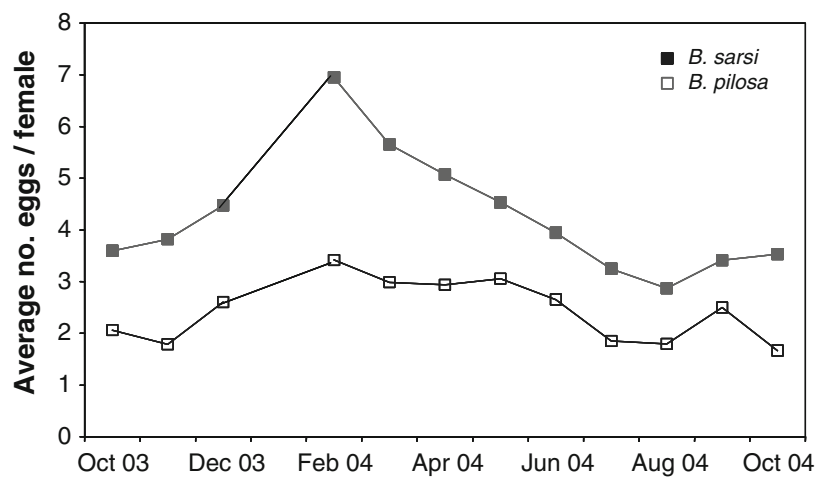

Fig. 4 Temporal variation of fecundity (average number of eggs per female). Error bars omitted for graphic representation 


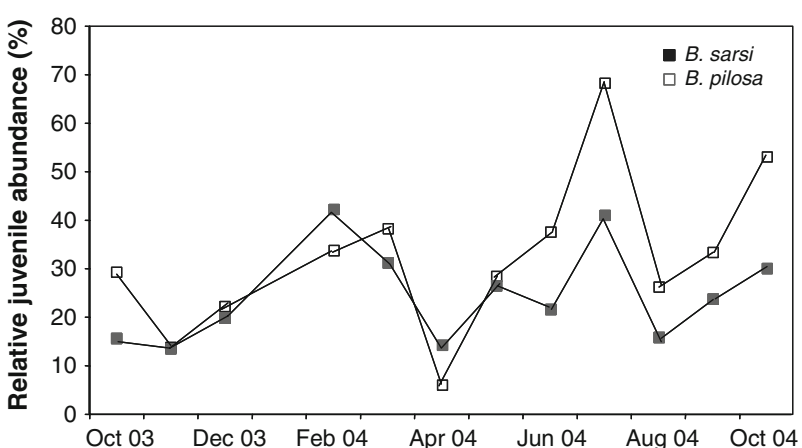

Fig. 5 Temporal variation of relative juvenile abundance. Error bars omitted for graphic representation

The sex ratio displayed a largely similar trend for both species, with about twice as much females as males from December 2003 until May 2004 (Fig. 6). From June 2004 onwards, a clear increase in female predominance was observed, up to ratios of six females per male. The only difference between the two species was found at the start of the sampling period (October-November 2003), when $B$. sarsi displayed a sex ratio similar to that of the summer months (up to six times more females), while B. pilosa already had the typical winter-spring ratio (about two times more females).

Mean annual biomass, secondary production and $\mathrm{P} / \mathrm{B}$ ratio (Table 1)

For B. pilosa, mean annual biomass (MAB), secondary production and $\mathrm{P} / \mathrm{B}$ ratio all reached clearly higher values

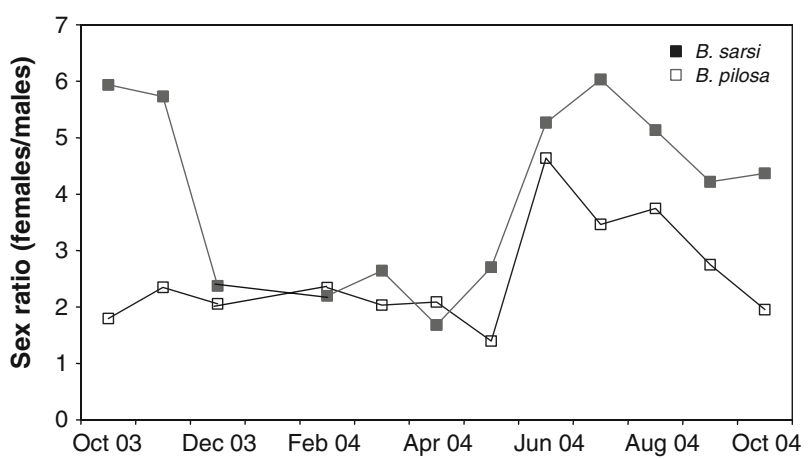

Fig. 6 Sex ratio (\#females/\#males) over time, solid squares B. sarsi, open squares B. pilosa. Error bars omitted for graphic representation

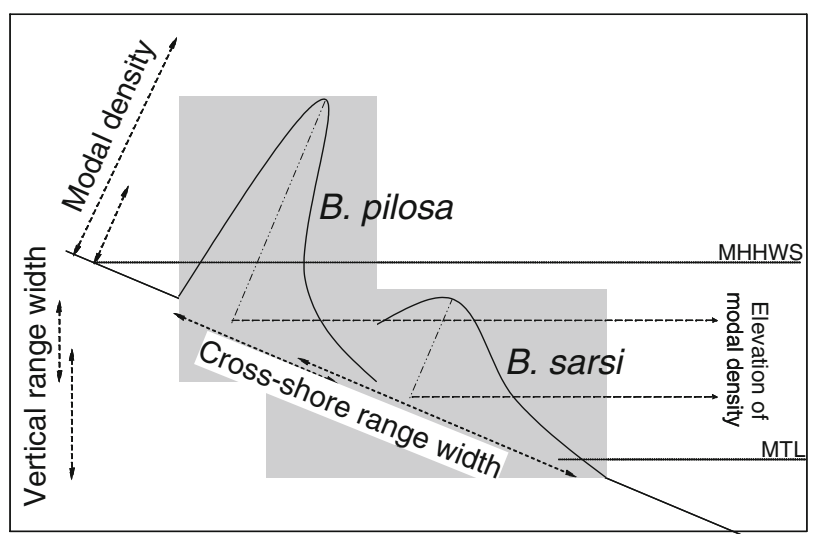

Fig. 7 Schematic representation of cross-shore distribution of Bathyporeia pilosa and B. sarsi across the intertidal gradient. $M H H W S$ level of mean highest high water at spring tide, $M T L$ mid-tidal level

along the western transects. $\mathrm{P} / \mathrm{B}$ ratios varied more than tenfold with regard to sampling location. Also in B. sarsi, large differences in the MAB values could be recognised, yet somatic production seemed to vary to the same degree, resulting in rather comparable $\mathrm{P} / \mathrm{B}$ ratio values for all beaches. Nevertheless, $\mathrm{P} / \mathrm{B}$ ratios show high productivity of the Nieuwpoort transects for both Bathyporeia species.

\section{Cross-shore zonation}

Figure 7 presents a schematic overview of the cross-shore distribution of the investigated species, introducing investigated variables. First, elevation of the maximum density sample of each transect at each sampling month is considered. Secondly, we address the width of the occupied vertical range.

Peak abundances of $B$. pilosa were found at $436 \pm 25 \mathrm{SD} \mathrm{cm}$ above mean lower low water springs (MLLWS), while those of $B$. sarsi were found at $357 \pm 40$ SD cm above MLLWS. B. pilosa was found significantly higher on the beach than $B$. sarsi (Wilcoxon matched pairs test: $Z=4.11 ; p<0.01)$. This vertical difference of about $80 \mathrm{~cm}$ corresponds (depending on beach slope) to a 40-62 m cross-shore distance.

Significant differences in elevation of peak abundance were found as well between the four transects under consideration for B. pilosa [Friedman $\chi^{2}$ Square $(N=10$, $d f=3)=14.39 ; p<0.01$ ] (Fig. 8-left).

Table 1 Mean annual biomass (MAB, mg AFDW/m²), secondary production (P-size frequency method, $\left.\mathrm{g} \mathrm{m}^{-2} \mathrm{y}^{-1}\right)$ and $\mathrm{P} / \mathrm{B}-\mathrm{ratio}\left(\mathrm{P} / \mathrm{B}, \mathrm{y}^{-1}\right)$

\begin{tabular}{|c|c|c|c|c|c|c|c|c|c|c|c|c|}
\hline & \multicolumn{3}{|l|}{ NP } & \multicolumn{3}{|l|}{ IJ } & \multicolumn{3}{|l|}{ MK } & \multicolumn{3}{|l|}{$\mathrm{OO}$} \\
\hline & MAB & P & $\mathrm{P} / \mathrm{B}$ & MAB & $\mathrm{P}$ & $\mathrm{P} / \mathrm{B}$ & MAB & $\mathrm{P}$ & $\mathrm{P} / \mathrm{B}$ & MAB & $\mathrm{P}$ & $\mathrm{P} / \mathrm{B}$ \\
\hline B. pilosa & 2,035 & 1,6040 & 7.88 & 1,458 & 10,165 & 6.97 & 9.13 & 28 & 3.08 & 3.10 & 1.84 & 0.59 \\
\hline B. sarsi & 1,005 & 7,580 & 7.54 & 209 & 1245 & 5.95 & 496 & 3,279 & 6.62 & 187 & 1,260 & 6.74 \\
\hline
\end{tabular}

$N P$ Nieuwpoort, $I J$ Ijzermonding, $M K$ Middelkerke, $O O$ Oostende 
Fig. 8 Spatial variation of elevation of peak abundance of Bathyporeia pilosa (left) and B. sarsi (right)(in cm). Box SE, whisker SD. Transects ordered from west (left) to east (right) in both graphs. MLLWS mean lower low water springs
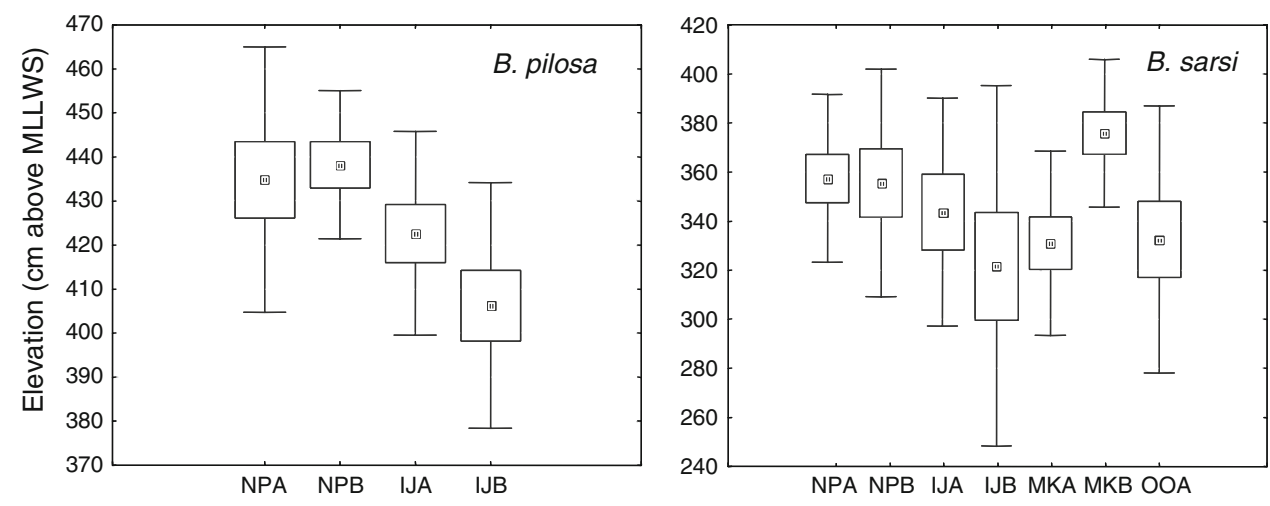

Fig. 9 Spatial (left-ransects ordered from west (left) to east (right) and temporal variation (right) of width of vertical range of Bathyporeia sarsi. Box SE, whisker SD

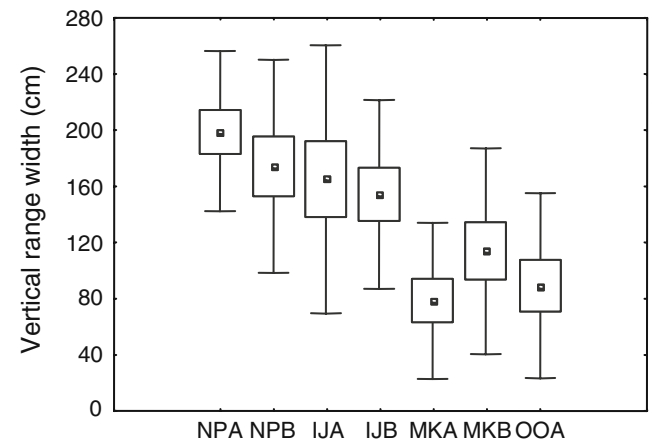

For B. sarsi, differences were significant at the $10 \%$ level [Friedman $\chi^{2}$ Square $(N=8, d f=6)=11.78 ; p=0.07$ ] (Fig. 8-right). Like in B. pilosa, there is a tendency of peak abundances occurring higher up on the beach of Nieuwpoort than on that of the Ijzermonding and a remarkable $40 \mathrm{~cm}$ difference between the two transects at Middelkerke.

Considering only western transects, no significant variation over time was observed [Friedman $\chi^{2}$ Square $(N=3$, $d f=10)=14.01 ; p=0.17]$ for $B$. pilosa. Yet, peak density elevation was highest from May to July and lowest from October to February. For $B$. sarsi there was significant variation over time [Friedman $\chi^{2}$ Square $(N=4$, $d f=11)=24.31 ; p=0.01$ ], with peak abundances being found higher up on the beach in summer. However, interannual variation (comparing October 2003 and October 2004) seems to be high as well.

For either species, no differences in modal height were detected between juveniles and adults (Wilcoxon matched pairs test: $B$. pilosa: $Z=1.069, p=0.29 ; B$. sarsi: $Z=0.1825, p=0.86$ ) nor between females versus males (Wilcoxon matched pairs test: B. pilosa: $Z=0.700$, $p=0.48$; B. sarsi: $Z=0.1778, p=0.86$ ). Thus, no evidence of intraspecific cross-shore segregation was found.

Comparing the two species (while considering western transects only), it is clear that B. sarsi occupies a wider vertical range or zone than $B$. pilosa (Wilcoxon matched pairs test: $Z=3.38, p<0.001)$. This difference is about $70 \mathrm{~cm}$ in vertical distance, corresponding to $35-54 \mathrm{~m}$ cross-shore.
Females of both species occupy a significantly wider zone than males (B. pilosa: Wilcoxon matched pairs test: $Z=2.52, p=0.01 ; B$. sarsi: Wilcoxon matched pairs test: $Z=2.37, p=0.02$ ), and, strikingly, the female range is an equal $30 \mathrm{~cm}$ wider in vertical distance $(15-23 \mathrm{~m}$ crossshore) in both species. Adults of B. pilosa, occupied a somewhat wider zone than juveniles (Wilcoxon matched pairs test: $Z=2.02, p=0.04$ ) with a difference of $10 \mathrm{~cm}$ in vertical distance (5-8 $\mathrm{m}$ cross-shore). For $B$. sarsi, this was only significant at the $10 \%$ level (Wilcoxon matched pairs test: $Z=1.85, p=0.06$ ), corresponding to about $20 \mathrm{~cm}$ vertical range difference (10-16 m cross-shore).

Comparing all transects for $B$. sarsi, vertical range width appeared to be significantly higher on western transects [Friedman $\chi^{2}$ Square $(N=12, d f=6)=30.02 ; p<0.01$ ] (Fig. 9-left), and the widest range was occupied in April, while autumn and winter values were lower [Friedman $\chi^{2}$ Square $(N=7, d f=11)=20.06 ; p=0.04$ ] (Fig. 9-right). For B. pilosa, it is most likely that the fact that only the western transects were available as replicates, disallowed observation of such differences [spatial: Friedman $\chi^{2}$ Square $(N=11, d f=3)=2.74 ; p=0.43$; temporal: Fried$\operatorname{man} \chi^{2}$ Square $\left.(N=4, d f=10)=4.76 ; p=0.91\right]$.

Median grain size related to peak abundance

Median grain size at stations of peak abundance along each transect were studied. For a reliable comparison of species, once more only western transects were considered. B. pilosa 
just failed to show significant differences between those transects (Friedman $\chi^{2}$ Square $(N=3, d f=3)=7.40$; $p=0.06]$, whereas significant differences were found for $B$. sarsi [Friedman $\chi^{2}$ Square $\left.(N=3, d f=3)=8.20 ; p=0.04\right]$.

\section{Discussion}

Abundance and biomass

At transects where the two species co-occurred in reasonable numbers, densities of $B$. sarsi were clearly lower than those of B. pilosa. Burrowed in the sand at low tide, B. pilosa seems to display a patchy distribution (Khayrallah and Jones 1980b; Persson 1982; Nicolaisen and Kanneworff 1983). Differences between observed densities and those found by other authors (Vader 1965; 1966; Salvat 1967; Persson 1982; Bamber 1993), might be attributed to differences in local habitat conditions, mainly tidal range, sediment characteristics and slope.

The presence of strong spatial abundance differences in B. pilosa and their absence in B. sarsi, might be attributed to small-scale differences in morphodynamics. The sampled eastern transects are somewhat less dissipative than the western ones (Degraer et al. 2003), as corroborated by a steeper slope and coarser sediment. This might concur with well established links between species richness and morphodynamics (e.g., Defeo and McLachlan 2005) but no such assessment is available from our data. Nicolaisen and Kanneworff (1969) stated that B. sarsi dominates on exposed shores, and $B$. pilosa on sheltered localities. In contrast to B. pilosa, B. sarsi seems to be able to cope with the somewhat more reflective conditions at the eastern transects. Vader (1965) stated that $B$. sarsi prefers, or better tolerates, somewhat coarser sands than $B$. pilosa, but both species have been found in finer as well as coarser sands. B. pilosa has been described as preferring fine sands containing some fines (Vader 1965, 1966). The content of fines was clearly lower along eastern transects (always practically zero).

In both species, biomass trends coincided with those in abundance, with a similar distinction between western and eastern transects. Yet, total biomass of B. pilosa at transect MKB was comparable with that at transect IJB, whereas abundance was clearly lower at MKB than at IJB. There is a remarkable contrast between the two species in abundance versus biomass patterns. At all western transects, B. pilosa abundance ranged from comparable to ten times higher than that of $B$. sarsi, whereas biomass was five to ten times higher in B. sarsi than in B. pilosa. Thus, predators of Bathyporeia are offered a choice between more abundant, smaller prey and somewhat larger, yet scarcer food items. Higher individual biomass of $B$. sarsi seems to relate only to their larger adult size, as the biomass increment with growth seems to be comparable for the two species.

Significant higher densities of $B$. sarsi, as observed in spring and early summer, might be artefacts attributable to random aggregations and/or sample size. Yet, comparable variations in density have been observed for B. pilosa in the past (Persson 1982; Nicolaisen and Kanneworff 1983). Fincham (1971) related low numbers in autumn and winter to mortality. Maranhão et al. (2001) showed water temperature and salinity to influence seasonal abundance changes in Echinogammarus marinus, with higher temperatures and salinity levels relating to lower densities. High temperatures might enhance desiccation of the animals during emersion periods, causing lower numbers in summer. However, on the studied Portuguese intertidal area winter temperatures may present less stress than they do on Belgian beaches. High densities earlier in the year may be attributable to a peak of successful reproduction in spring and rising temperatures after spring, creating favourable conditions for development and reproduction.

Life cycle, demography, reproduction and recruitment

Confusing output of the cohort analysis made it hard to unravel Bathyporeia life history; cohorts were often inseparable due to continuous reproduction. This is not new for these species (Fish and Preece 1970a). Nevertheless, two peaks of reproduction, as indicated by the relative abundance of gravid females and to a large degree corroborated by trends in fecundity and juvenile abundance, were visible in this study. Peaks in the relative abundance of gravid females were pretty much in concordance with earlier findings (Salvat 1967; Fish and Preece 1970a) and can be summarised as a (broader) spring peak and an autumn peak. Timing of these peaks may differ slightly between locations and probably years, due to small differences in microclimate and food availability. Lower reproductive activity in winter and summer is probably an indirect effect of increased female mortality after reproduction (see gravid females relative abundance and sex ratio data). In contrast to Fish (1975), only a single peak of relative abundance of males (in October for B. pilosa; in April in B. sarsi) was apparent, coinciding with the peak in gravid females relative abundance, rather than preceding it. It is likely that our sampling frequency was too low to observe the exact subsequence.

Mettam (1989) also found sex ratio to be shifted towards female predominance, but observed a nearly equilibrium during the major reproduction peak. This was not the case in our Belgian populations, where male relative abundance peaked in May, being still 50\% less than female abundance. From June until the end of summer, five to six times more females were observed. Mettam (1989) suggested this 
might be due to slower growth and shorter life span in males and difficulties in sexing juveniles. Watkin (1939) attributed these differences to sampling method (towing versus digging). Digging samples out, like we did, should however reflect the population at best.

As sex ratio, also fecundity (number of embryos per female) showed a highly comparable trend in the two species, peaking in February and again but less sharp in autumn. The lower fecundity of B. pilosa showed less clear peaking, with a rather continuous period of higher fecundity from February to May and an additional peak in September. Fecundity peaking in spring was also found by Fish (1975), with lower values afterwards due to adult mortality. Maranhão et al. (2001) related lower fecundity to lower temperature and salinity drops due to rainfall. Lower fecundity in those conditions should favour somatic development. This could also be the case for Belgian B. pilosa in autumn and early winter, yet peak fecundity was observed as soon as February. This might have been due to the mild winter of 2003-2004. The observed correlation between fecundity and female body size is well known for several amphipods (Fish 1975).

Differences in fecundity between B. pilosa and B. sarsi indicate a different reproduction strategy (cf. Maranhão et al. 2001). B. pilosa has fewer embryos of larger size and higher yolk content, giving individual embryos a higher chance of survival, probably as a response to the species' more stressful environment in the highest parts of the intertidal zone (strong fluctuations in temperature, salinity and sediment water content). Gonad production showed energy costs for both strategies to be of the same magnitude.

Continuous recruitment occurs but is low in between recruitment peaks. Fish (1975) mentioned hatchlings size of about $1.5 \mathrm{~mm}$. In the present study, the applied mesh width did not allow retention of animals of this size. This may have resulted in a loss of data in cohort analysis and the study of age/size-based cross-shore segregation. Furthermore, monthly sampling might cause new recruitment to be observed not until after some weeks of growth. The smallest individual found in the present study was $1.977 \mathrm{~mm}$ in length. Three peaks of recruitment were suggested by the appearance of new cohorts and by peaks in relative juvenile abundance (February-March, July and October). Remarkably, the July peak in relative juvenile abundance did not coincide with a peak in neither relative abundance of gravid females nor fecundity. Yet, sex ratio did and higher proportional numbers of females in June-July may have compensated for lower fecundity and the lower relative abundance of gravid females. However, it is probably adult mortality, as observed by a drop in biomass in July samples, which explains the July peak in relative juvenile abundance, and the shift in sex-ratio may be due to a (relatively) higher male mortality. A 'spring plus autumn' recruitment peak scenario seems most likely and is confirmed by the fecundity data, absolute numbers of juveniles per month and the output of the cohort analysis, showing new cohorts appearing in February and October. Thus, a bivoltine life cycle was observed, with a broad spring peak of reproductive activity and recruitment and a second, much smaller one in autumn, which may slightly vary in magnitude and timing from one location to another.

Some interesting temporal spring-autumn and year-toyear differences require further discussion. In B. pilosa, spring females are larger than autumn ones, formerly explained as a consequence of a longer period of growth (Fish and Preece 1970a). Yet, individuals hatched in February have six to seven months to grow before they reproduce, as have the wintering ones, born in autumn. The spring reproduction peak is, however, rather wide and lasts in fact until May, giving late hatchlings little time to grow over the summer and thus, perhaps, resulting in lower average adult size.

\section{Growth and mortality}

As the output of the cohort analysis provided confusing results, a growth function could not be defined.

The magnitude of adult cohort growth, observed in part from one month to the next, suggests quasi-linear growth in the investigated populations of the two species. In juvenile cohorts, continuous reproduction and recruitment, together with considerable juvenile mortality, seem to induce strong monthly oscillations in average cohort body length, disallowing assessment of growth. There seems to be no indication of different growth rates in the two species, as slopes of the calculated regressions were highly similar (B. pilosa: 0.2687 ; B. sarsi: 0.2616 ). Yet, given a comparable life span of the two species, but larger adult size and smaller eggs (and thus probably smaller hatchlings) in B. sarsi, the latter might be thought to grow faster. This might be also facilitated by more benign habitat conditions somewhat lower on the beach, where $B$. sarsi reaches highest numbers. The available data, however, shows $B$. sarsi juveniles of February and October to be $1 \mathrm{~mm}$ larger on average than those of B. pilosa. This confusing phenomenon has to be considered in view of the snapshot nature of monthly sampling. More frequent sampling, combined with sieving over a finer mesh, seems desirable.

Also mortality could not be quantified, as small monthto-month variations do not necessarily reflect mortality, but can be caused by accidental aggregations of individuals (Defeo and McLachlan 2005). Disappearance of entire adult cohorts might, however, indicate mortality more reliably. This seems to occur from June to July, when the disappearance of adults causes a drop in biomass. The described bivoltine life cycle of the species, with two 
generations per year (as also found by Salvat 1967; Fish and Preece 1970a), explains two peaks in adult mortality coinciding with the disappearance of adult cohorts in February and July. B. pilosa is highly tolerant to various forms of environmental stress (Mettam 1989), while B. sarsi's stress tolerance may be lower (Vader 1965). Nicolaisen and Kanneworff (1983) mentioned a discrete episode of high mortality in a population from Denmark during the reproductive season, from May to September, most likely in both juveniles and adults. Winter mortality until March and summer mortality at least seem to confirm the existence of two generations per year.

\section{Secondary production}

$\mathrm{P} / \mathrm{B}$ ratios for $B$. pilosa showed clear differences between beaches, with eastern beaches delivering ratios half those of western ones (see Table 1). To assess the value of the studied beaches for higher trophic levels, total macrobenthic biomass should be considered besides other factors, e.g., levels of disturbance for wading birds as potential predators. In any case, the eastern beaches showed both low abundance and low $\mathrm{P} / \mathrm{B}$ ratios for B. pilosa. Higher P/B ratios, as found on the western beaches, are comparable to those found by Maranhão et al. (2001) for E. marinus (from 4.14 to 6.56 ). In contrast, $\mathrm{P} / \mathrm{B}$ ratios of B.sarsi were highly similar for all beaches. Thus, intertidal B. pilosa can, if present, provide a highly abundant food source for any predator able to manage itself in the upper parts of the intertidal zone. Also B. sarsi is a fairly abundant food source, but it is more widespread across the shore and occupies a part of the intertidal zone that might be easier to reach for submerged predators.

Habitat (1): cross-shore zonation

Bathyporeia pilosa was always found higher up on the beach than $B$. sarsi, confirmating earlier studies (e.g., Salvat 1962, 1964; Degraer et al. 2003). Peak abundances of B. pilosa occurred always above $4 \mathrm{~m}$ above MLLWS, while modal density of $B$. sarsi was found between 3 and $4 \mathrm{~m}$ above MLLWS. Our results demonstrate different optimal elevations for the two species, without strict separation. No intraspecific segregation by sex or age was observed for either species, and neither did Nicolaisen and Kanneworff (1983).

No significant seasonal migration was observed for $B$. pilosa, while contrasting results have been obtained in the past (Salvat 1967; Fish and Preece 1970a; Persson 1982). Most likely, differences in the studied habitat type can explain this: Fish and Preece (1970a) investigated an estuarine population, while Persson (1982) worked at the Baltic Sea. Temperature, light intensity and length of day might trigger seasonal migration, somewhat complicating comparison between studies. Our intertidal sandy beach population seemed to show a more onshore presence from the end of summer until November. Fish and Preece (1970a) found the animals situated higher up on the beach between November and March. Though generally confusing, differences in climate and hydrology might explain this. Stress by desiccation (mainly in summer) might be less immanent on Belgian beaches, whereas freezing in winter might urge animals to migrate to areas of longer submersion, buffered in temperature and less subjected to storms and heavy rainfall. Further, on beaches where runnels are present, highest numbers of $B$. pilosa but also of $B$. sarsi have been observed within these runnels, retaining water throughout the tidal cycle (pers. obs.). This might cause both seaward and landward, or better 'runnelward', migration in autumn. In contrast, B. sarsi displayed a clear seaward shift of animals from January to March, comparable to findings of Nicolaisen and Kanneworff (1983) in the Baltic Sea and to what Persson (1982) described for B. pilosa. Again, animals were found higher up in summer.

Habitat (2): width of the occupied vertical range

Bathyporeia sarsi occupies a wider vertical, and thus also cross-shore, range on the beach than B. pilosa. Range width might be related to abundance, thus explaining a narrower range of $B$. pilosa at the Ijzermonding beach. Differences between eastern and western transects in $B$. sarsi might be due to established differences in median grain size and beach slope, causing harsher conditions on eastern transects and resulting in lower abundance and smaller vertical range width. In October 2004 the zone occupied by B. pilosa was wider than in October 2003, perhaps due to interannual variation in temperature, wave energy, food supply and/or patchiness.

Interestingly, in both species females occupied a wider range than males, concurring Preece's $(1970,1971 a)$ experimental results for $B$. pilosa, and demonstrating higher stress tolerance of females towards extremes in temperature and salinity, even though Preece's results might have been hampered by the shorter male life span. Furthermore, range width was higher in adults (being mainly females) than in juveniles. Combining sex and age analysis was not possible due to too small numbers remaining within each category.

Finally, it is striking that the species inhabiting the widest range (B. sarsi) shows the fewest evidence of intraspecific cross-shore segregation.

Habitat (3): median grain size at peak abundance

Significant spatial differences in median grain size and apparent differences between the two species in median 
grain size at stations of peak abundance were observed. These cannot be considered independently from the differences in elevation of the abundance peaks. Observed nonsignificant seasonal changes in the relation between grain size and abundance are most likely an indirect effect of seasonal migration, caused by climate and hydrology. Sands on the investigated beaches were largely situated well within mentioned ranges of tolerance for both species, although Vader (1965) stated B. sarsi to prefer somewhat coarser sands and to be more tolerant regarding grain size than B. pilosa. Still, differences in exposition as mentioned by Nicolaisen and Kanneworff (1969) seem to be more explanatory than strict grain size responses.

Acknowledgments This research was funded by the Flemish Coastal Waterways Division (AWZ-WWK, now called Agency of Maritime and Coastal Services (MDK) - Coastal Division, contract number 204.295), the Research Foundation-Flanders (FWO-Vlaanderen, KISS-project, registration number G048005), and Ghent University (UGent project GOA 01G00705). Francisco Hernandez (VLIZ-Flanders Marine Institute) is thanked for providing elevation data. Many colleagues and students at the UGent Marine Biology lab are thanked for their highly appreciated help in the field.

\section{References}

Bamber RN (1993) Changes in the infauna of a sandy beach. J Exp Mar Biol Ecol 172:93-107

Beyst B, Vanaverbeke J, Vincx M, Mees J (2002) Tidal and diurnal periodicity in macrocrustaceans and demersal fish of an exposed sandy beach with special emphasis on juvenile plaice Pleuronectes platessa. Mar Ecol Prog Ser 225:263-274

Bhattacharya CG (1967) A simple method of resolution of a distribution into Gaussian components. Biometrics 23:115-135

Dahl E (1944) Smärre undersökningar över Öresund. 10. The Swedish water malacostraca. Kungliga Fysiografiska Sällskapets Lund Förhanlingar 14:1-17

Defeo O, McLachlan A (2005) Patterns, processes and regulatory mechanisms in sandy beach macrofauna: a multi-scale analysis. Mar Ecol Prog Ser 295:1-20

Degraer S, Van Hoey G, Wittoeck J, Vincx M (2002) Huidige situatie en autonome ontwikkeling, partim benthos. Report prepared for Zeeland Seaports within the framework of the EIS for zones of sandextraction in front of Zeeland (The Netherlands). UGent

Degraer S, Volckaert A, Vincx M (2003) Macrobenthic zonation patterns along a morphodynamical continuum of macrotidal, low tide bar/rip and ultra-dissipative sandy beaches. Estuar Coast Shelf Sci 56:459-468

d'Udekem d'Acoz C (2004) The genus Bathyporeia Lindström, 1855, in western Europe (Crustacea: Amphipoda: Pontoporeiidae). Zoologische Verhandelingen 348:1-162

Fincham AA (1971) Ecology and population studies of some intertidal and sublittoral sand-dwelling amphipods. J Mar Biol Ass UK 51:471-488

Fish JD (1975) Development, hatching and brood size in Bathyporeia pilosa en $B$. pelagica (Crustacea: Amphipoda). J Mar Biol Ass UK 55:357-368

Fish JD, Preece GD (1970a) The annual reproductive patterns of Bathyporeia pilosa and Bathyporeia pelagica (Crustacea: Amphipoda). J Mar Biol Ass UK 50:475-488
Fish JD, Preece GD (1970b) The ecophysiological complex of Bathyporeia pilosa and B. pelagica (Crustacea: Amphipoda). 1. Respiration rates. Mar Biol 5:22-28

Gayanilo FC Jr, Sparee P, Pauly D (1996) The FAO-ICLARM stock assessment tools (FiSAT) user's guide. FAO computerized information series (Fisheries). No. 8, FAO, Rome

Gibson RN, Robb L (1996) Piscine predation on juvenile fishes on a Scottish sandy beach. J Fish Biol 49:120-138

Hasselblad V (1966) Estimation of parameters for mixture of normal distributions. Technometrics 8:431-444

Hynes HBN, Coleman MJ (1968) A simple method of assessing the annual production of stream benthos. Limnol Oceanogr 13:569-573

Khayrallah NH, Jones AM (1980a) The ecology of Bathyporeia pilosa (Amphipoda: Haustoriidae) in the Tay Estuary. 1. Factors influencing the distribution on Tayport and Tentsmuir beaches. Proc Roy Soc Edinb B 78:109-119

Khayrallah NH, Jones AM (1980b) The ecology of Bathyporeia pilosa (Amphipoda: Haustoriidae) in the Tay Estuary. 2. Factors affecting the micro-distribution. Proc Roy Soc Edinb B 78:121-130

Köhn J, Gosselck F (1989) Bestimmungsschlüssel der Malacostraken der Ostsee. Mitteil Zool Mus Berlin 65:3-114

Köhn J, Sammour M (1990) Lebensgeschichte und Produktion von Bathyporeia Lindström, 1855 (Amphipoda, Haustoriidae) in der westlichen Ostsee. Zool Anz 224:165-174

Lasiak TA (1983) The impact of surf-zone fish communities on faunal assemblages associated with sandy beaches. In: McLachlan A, Erasmus T (eds) Sandy beaches as ecosystems. Dr W. Junk Publishers, The Hague, pp 501-506

Lindström G (1855) Bidrag till kännedomen om Östersjöns invertebrafauna. Öfversigt af Kongliga Vetenskaps-Akademiens Förhandlingar 12:49-73

Maranhão P, Bengala N, Pardal M, Marques JC (2001) The influence of environmental factors on the population dynamics, reproductive biology and productivity of Echinogammarus marinus Leach (Amphipoda, Gammaridae) in the Mondego estuary (Portugal). Acta Oecol 22:139-152

Marques JC, Bellan-Santini D (1991) Gammaridea and Caprellidea (Crustacea-Amphipoda) of the Portuguese south-western continental shelf: taxonomy and distributional ecology. Bijdr Dierkd 61:65-87

McLachlan A, Dorvlo A (2005) Global patterns in sandy beach macrobenthic communities. J Coastal Res 21:674-687

Mettam C (1989) The life cycle of Bathyporeia pilosa Lindström (Amphipoda) in a stressful, low salinity environment. Sci Mar 53:543-550

Nicolaisen W, Kanneworff E (1969) On the burrowing and feeding habits of the amphipods Bathyporeia pilosa Lindström and Bathyporeia sarsi Watkin. Ophelia 6:231-250

Nicolaisen W, Kanneworff E (1983) Annual variations in vertical distribution and density of Bathyporeia pilosa Lindström and Bathyporeia sarsi Watkin at Julebaek (North-Sealand, Denmark). Ophelia 22:237-251

Persson L-E (1982) Seasonal migration of Bathyporeia pilosa Lindström in the southern Baltic. Ophelia 21:205-213

Preece GS (1970) Salinity and survival in Bathyporeia pilosa Lindström and B. pelagica (Bate). J Exp Mar Biol Ecol 5:234-245

Preece GS (1971a) The ecophysiological complex of Bathyporeia pilosa and B. pelagica (Crustacea: Amphipoda). 2. Effects of exposure. Mar Biol 11:28-34

Preece GS (1971b) The swimming rhythm of Bathyporeia pilosa (Crustacea: Amphipoda). J Mar Biol Ass UK 51:777-791

Salvat B (1962) Faune des sédiments meubles intertidaux du Bassin d'Arachon. Systématique et Ecologie. Cah Biol Mar 28:207-223

Salvat B (1964) Les conditions hydrodynamiques interstitielles des sédiments meubles intertidaux et la répartition verticale de la faune endogée. CR Acad Sci Paris 259:1576-1579 
Salvat B (1967) La macrofaune carcinologique endogée des sédiments meubles intertidaux (Tanaidacés, Isopodes et Amphipodes), éthologie, bionomie, et cycle biologique. Mém Mus Nation Hist Nat Paris (A) 45:1-275

Short AD (1999) Handbook of beach and shore morphodynamics. Wiley, London

Sundbäck K, Persson LE (1981) The effect of microbenthic grazing by an amphipod, Bathyporeia pilosa, Lindström. Kieler Meererforsch 5:573-575

Tomlinson PK (1971) NORMSEP: normal distribution separation. In: Abramson N (ed) Computer programs for fish stock assessment. FAO Fisheries technical papers 101
Toulmond A (1964) Les Amphipodes des faciès sableux intertidaux de Roscoff. Aperçus faunistiques et écologiques. Cah Biol Mar 5:319-342

Vader W (1965) Intertidal distribution of haustoriid amphipods in The Netherlands. Botanica Gothoburgensia 3:233-246

Vader W (1966) Een overzicht van de zandbewonende Amphipoden uit het Oosterschelde gebied. Het Zeepaard 26:102-124

Watkin EE (1938) A revision of the amphipod genus Bathyporeia Lindström. J Mar Biol Ass UK 23:211-236

Watkin EE (1939) The pelagic phase in the life history of the amphipod genus Bathyporeia. J Mar Biol Ass UK 23:467-481 